\title{
Juventude, caminho aberto?
}

Pe José Abel de Souza, SJ. ${ }^{1}$

\section{Introdução}

O tema da Campanha da Fraternidade (CF) da CNBB do ano de 1992 teve como tema "Juventude - caminho aberto". Em outubro de 2018 houve, em Roma, o XV Sínodo Ordinário dos Bispos, convocado pelo papa Francisco, com o tema: "Os jovens, a fé e o discernimento vocacional". Essas duas iniciativas, dentre muitas outras, como as Jornadas Mundiais da Juventude, exemplificam que a Igreja católica no Brasil e no mundo tem se preocupado com a juventude. Malgrado esse esforço, muito falta para que a Igreja possa cultivar o sentimento do dever cumprido. Intitulei este artigo retomando o tema da CF da CNBB de 1992, porém, adicionando um ponto de interrogação. A ênfase será na juventude universitária. Busco apresentar questões advindas de anseios dos jovens a serem respondidas pela Igreja, especialmente pela Teologia e pela universidade católica como um todo e em sintonia com os jovens.

\section{1) Características da realidade social das juventudes na universidade católica atual}

No Brasil, particularmente, as últimas duas décadas, graças a políticas governamentais de inclusão universitária como Prouni, FIES acompanhadas de cursinhos pré-vestibulares comunitários, acolheram um significativo aumento no número de jovens das classes populares com acesso ao ensino superior. No caso das universidades católicas, elas pertencem à categoria das universidades comunitárias, distintas tanto das privadas, como das estatais, uma condição que possibilita que concedam bolsas de estudo a jovens de baixa renda. Essa realidade favoreceu que, por exemplo, a PUC-Rio deixasse de ser uma universidade quase que exclusivamente de jovens abastados e que um número expressivo de estudantes de classes sociais menos

\footnotetext{
${ }^{1}$ Bacharel em Filosofia, mestre em Teologia Bíblica e doutorando em Teologia 
favorecidas ingressasse na universidade na condição de bolsistas. Porém, nem tudo se revelou "flores". Enquanto os tradicionais estudantes da classe alta ostentam orgulhosamente o título de "filhos da PUC", os de classe social baixa muitas vezes se percebem na condição de "bastardos da PUC".

Infelizmente, não há como sustentar que esses estudantes "bastardos" estejam exagerando essa percepção ou mesmo que se tratem de casos isolados. A realidade é complexa e ganhou notoriedade depois da morte da vereadora Marielle Franco. Em primeiro lugar, porque o assassinato dela teve grande repercussão inclusive em âmbito mundial, mas, principalmente, porque ela mesma foi uma estudante "bastarda" - pouco antes de ser assassinada esteve presente justamente no lançamento do coletivo denominado Bastardos da PUC-Rio, composto por estudantes pobres da universidade. $\mathrm{Na}$ ocasião, a parlamentar escreveu uma carta cujo título é: "Aos 'bastardos da PUC', com carinho". O conteúdo dessa carta de cunho testemunhal é otimista, diz ela que "ser um filho 'bastardo' da PUC-Rio não pode ser encarado como algo ruim, precisamos reivindicar um novo significado político: o 'bastardo' é aquele que resiste às desigualdades". Marielle afirma, ainda, que

sem perder de vista a nossa identidade, o lugar e a família que nos gestaram, viver a PUC-Rio é quase uma missão política e social, já que o processo pedagógico é uma via de mão dupla: quando nos transformamos, modificamos também tudo e todos à nossa volta. A nossa presença na PUC-Rio já é, por si só, um ato de resistência. (Franco, 2017)

O tom otimista e proativo de Marielle não visa esconder as dificuldades enfrentadas por ela própria e pelos atuais estudantes de baixa renda, pois, segundo ela,

(...) é impossível não sentir aquele frio na barriga! Ainda mais quando ouvimos aquelas histórias de que há professores que dão textos e filmes em inglês sem tradução, de que não se veem alunos e professores negros em sala de aula, de que a principal reivindicação estudantil é a diminuição do preço do estacionamento, de que o pilotis da PUC é um desfile de moda... e por aí vai. (Franco, 2017)

Marielle, ao mesmo tempo que põe o dedo na ferida, aponta para a necessidade de se buscar novas perspectivas: "apresentar para quem quer que seja a nossa realidade concreta não é ser vitimista, 
ainda mais com a perspectiva de trilhar caminhos possíveis e alternativos às limitações encontradas". Ela reconhece o esforço feito pelo governo da instituição em favor da inclusão: “(...) a vice-reitoria comunitária também é uma parceira fundamental para questões objetivas e para oportunidades dentro e fora da universidade". E mais: "É importante cercar-se de pessoas, sejam colegas de turma, professores ou funcionários, que possam contribuir para que a passagem pela PUC seja plena" (Franco, 2017). Essas palavras de Marielle Franco vão ao encontro do que afirma o atual reitor quanto à busca de inclusão social: “(...) mesmo na revisão da política de bolsas, feita em razão de equilíbrio financeiro, procuramos manter um índice elevado delas, atingindo hoje quase a metade dos alunos de graduação" (Siqueira, 2018:113). A isso se somam muitas outras iniciativas da PUC-Rio no objetivo de acolhimento e busca da diminuição da desigualdade social.

Mesmo com todo esse meritório esforço, a universidade católica está longe de conseguir resolver o problema da desigualdade social que transcende os seus muros (Silva, 2003). Atitudes preconceituosas por parte de professores, funcionários e de estudantes, por mais reprováveis que sejam, infelizmente existem e em uma instituição da dimensão da PUC-Rio é praticamente impossível evitar que, pelo menos, algum caso ocorra. O que nos anima é a comprovação de que o empenho em favor da inclusão social e a defesa da dignidade humana na PUC-Rio estão entre as características mais sublimes da instituição. Contudo, por mais que a universidade se esforce, as consequências da desigualdade social seguirão existindo, haja vista que os estudantes mais pobres provém de escolas públicas, nas quais, salvo raras exceções, a qualidade do ensino é incomparavelmente mais fraca que a dos estudantes ricos que puderam frequentar uma escola particular (Zago, 2006). Enquanto os ricos, em geral, podem percorrer o trajeto da residência à universidade de carro, os pobres necessitam gastar longas horas em transportes públicos sem nenhum conforto, isso para citar apenas alguns exemplos, dentre muitos outros que ilustram o abismo que há entre um estudante de classe alta e outro de classe baixa. Portanto, mesmo que a PUC-Rio, no seu interior, chegue a um grau de inclusão social muito acima da média, ainda assim seguirão existindo os "bastardos" da sociedade dentro dela. Como especifica Marielle 
Franco na missiva (2017), “(...) buscar compreender a PUC-Rio em sua complexidade, enquanto uma universidade privada de qualidade e legitimidade acadêmica, é também entender que, em uma sociedade desigual, racista e machista, as raras oportunidades não devem ser subutilizadas", pois, não obstante todos os desafios, o esforço da universidade em acolher da melhor maneira possível o estudante de classe pobre e deste em fazer jus e valorizar essa oportunidade é um significativo passo em favor da construção de uma sociedade mais justa e mais solidária.

Já há algum tempo se tem dado preferência ao termo juventudes no plural, expressando assim o desejo de valorizar a diversidade de perfis de jovens, diversidades essas que vão muito além daquela tradicional entre rico e pobre acima mencionada. Cresce cada vez mais na universidade católica a importância do diálogo, do respeito e da valorização da pluralidade cultural e da diversidade religiosa.

\section{2) Características do perfil religioso e espiritual das juventudes na universidade católica}

O Sínodo sobre a juventude realizado em outubro de 2018 possibilitou que jovens representantes das diversas regiões do mundo tivessem a oportunidade de estar inseridos nesse acontecimento eclesial e ouvir que a Igreja se preocupa com eles. Quer ouvi-los, captar seus desejos e aspirações, falar-lhes. Fazê-los sentir que, nestes tempos de incertezas que vivemos, eles são o presente e a esperança de futuro. O tema da CF do ano de 1992, Juventude, caminho aberto, segue sendo de grande atualidade mesmo depois quase trinta anos. O texto base da CF daquele ano dizia que Jesus é o caminho: "Jesus que nos dá a certeza de que Ele continua fazendo história conosco e de que a cruz não é o fim, mas o caminho da vitória para os que O seguem" (CNBB, 1992:n.135). Que Jesus seja o caminho, por excelência, pelo menos para os jovens cristãos, sempre foi e sempre será verdadeiro e também muito importante. Porém, são inúmeros os desafios a que os jovens estão expostos, conforme a teóloga M. C. Bingemer publicou em um artigo no Jornal do Brasil, logo após o término do Sínodo, cujo título é expressivo: "Ser jovem em tempos tenebrosos". Ressalta ela que "é difícil ser jovem hoje em dia. As relações afetivas são voláteis e frustrantes. O futuro profissional 
inexiste e muitas vezes anos de estudo e preparação desembocam no lodaçal viscoso e repugnante do desemprego e da falta de oportunidades". É a essas juventudes que se dirigiu a Igreja católica reunida em sínodo, no desejo de estabelecer um verdadeiro diálogo com a geração que hoje vive em meio às diversas ameaças e à falta de horizontes. É evidente que os mais pobres são sempre os mais sacrificados, porém, como se trata de uma crise do sentido da vida, ela afeta de um modo ou de outro a todos.

O Sínodo constatou que nas juventudes de hoje, mesmo com todos os problemas e contínuos estímulos a elas lançados pela globalização, pela secularização e pelos desertos contemporâneos, segue existindo a sede de Deus e a busca de espiritualidade. É fato que, particularmente no ambiente universitário, se busca cada vez menos religião, embora continue havendo abertura para uma espiritualidade que favoreça a construção do sentido da vida e que ajude a viver. Por isso, a Igreja e a Teologia se sentem desafiadas a recuperar a importância do dinamismo da fé em seu diálogo com as novas gerações.

Bingemer chama atenção da hierarquia da lgreja dizendo que "já é mais que hora de falar a verdade aos jovens. É imperioso que a Igreja se mostre a eles e elas com sua verdadeira face. Sem filtros. Sem camuflagens. Trata-se da Igreja de Cristo, santa e pecadora" (Bingemer, 2018). A Igreja católica como um todo, mas principalmente no ambiente universitário, tem que adotar uma atitude de humildade e ter a coragem de mostrar-se tal qual é, inclusive pedir perdão por erros cometidos. Só assim terá credibilidade junto aos jovens e será, então, muito mais capaz de acompanhá-los em seus discernimentos e escolhas, acolhendo-os como mãe carinhosa e amiga, com seus defeitos e qualidades. Nessa relação sempre renovada pela verdade, poderá se abrir o caminho do diálogo entre as juventudes e a Igreja católica. Há ainda inúmeros obstáculos a serem superados, mas, a Igreja católica sob a liderança dos últimos papas tem progredido nessa consciência, como se pode ver na afirmação do papa Francisco na Jornada Mundial da Juventude no Rio de Janeiro: "as juventudes são chamadas a mostrar e viver um caminho de comunhão, respeito e diálogo".

Na encíclica Laudato Si', o papa Francisco fala de educar para a aliança entre a humanidade e o ambiente: "os jovens têm uma nova 
sensibilidade ecológica e espírito generoso, e alguns deles lutam admiravelmente pela defesa do meio ambiente" (n.209). "Trata-se da convicção de que 'quanto menos, tanto mais' (...). A espiritualidade cristã propõe um crescimento na sobriedade e uma capacidade de se alegrar com pouco" (n.222). "A sobriedade, vivida livre e conscientemente, é libertadora" (n.223). As novas gerações podem e devem ser tocadas por esse desafio do "quanto menos, tanto mais", fazendo frente ao consumismo e à consequente destruição da natureza, da casa comum. Nas mãos das juventudes está também o desafio de cuidar do presente e do futuro do planeta. E uma das maneiras de iniciar são os chamados "quatro erres": reduzir, reutilizar, reciclar e reparar. Este é um dos caminhos que as juventudes podem trilhar, e serem convidadas a viver e a divulgar. Com efeito, o consumo equilibrado de energia, de matérias-primas e recursos naturais é significativo e são caminhos simples, concretos e possíveis de serem trilhados pelos jovens em seus diferentes grupos, de diferentes realidades socioculturais e regiões geográficas. O papa Francisco diz aos jovens:

Assim integrados nas suas comunidades, não tenham medo de arriscar-se e comprometer-se na construção de uma nova sociedade, permeando com a força do evangelho os ambientes sociais, políticos, econômicos e universitários! Não tenham medo de lutar contra a corrupção e não se deixem seduzir por ela! (Francisco, 2017).

Todo ser humano é naturalmente um ser ético, com alguma abertura para o transcendente. Todas as pessoas, de um modo ou de outro, se deparam com questões existenciais tais como: quem é o ser humano? Que sentido tem a vida? O que acontecerá depois da morte? Na sociedade moderna, pós-moderna, no pós-cristandade, há uma forte tendência a que nem a ética nem a religião incidam sobre as leis econômicas, nem sobre as políticas pragmáticas que regem este mundo. Vigora como que um pacto segundo o qual a sociedade oferece satisfação por meio de consumo cada vez mais ampliado, prometendo também respeitar as preferências estéticas, as escolhas, inclusive as religiosas, com uma liberdade subjetiva ilimitada, tudo isso desde que não interfiram no seu reino terreno. As juventudes podem ser induzidas pelo mercado consumista em direção às formas de religião desprovidas de ética, de racionalidade, de consciência de 
responsabilidade sobre o que acontece no mundo, portanto, sem avaliar criticamente os poderes políticos e econômicos que atuam segundo suas próprias regras e princípios (Libanio, 2011).

A consequência disso é que grandes problemas globais como a miséria, a violência, o cuidado e a não destruição do habitat da terra, assim como a reflexão acerca da qualidade de vida, o apreço pela diversidade cultural e o diálogo entre povos diversos parecem ficar totalmente alheios à dinâmica econômico-política e também à religião, que desprovida de sua incidência ética perde força quanto ao empenho em fazer a vida razoavelmente humana para todos. Essa espécie de pacto de convivência entre uma ordem político-econômica objetiva, que oferece a ilusão de felicidade atrelada a um consumo desenfreado e em permanente renovação, e variados modos subjetivos de viver as mais diferentes religiosidades e éticas sem incidir na ordem econômica vigente são as formas pós-modernas ao estilo new age.

As juventudes têm as perguntas existenciais de sempre; ocorre que cada vez mais elas aparecem embutidas nas novas tecnologias. Diante disso, emergem para os educadores e evangelizadores desafios e questões: "sabemos que as novas tecnologias podem ser usadas para o bem ou para o mal (...)"; "devemos animar os jovens sobre o uso inteligente e prudente da internet? (...)"; "a internet poderia ser utilizada mais amplamente para (...)"; "importante para o desenvolvimento do trabalho com os jovens (...)"; "uma inovação que possui dois polos (...)"; "em parte é bom o desenvolvimento digital (...)"; "pode ser considerada uma revolução e não apenas mudança (...)"; "hoje é um grande desafio prescindir da virtualidade em favor da realidade (...)". Por mais desafiador que seja, cabe à universidade católica, antes de tudo, o papel de compreender os jovens a fim de Ihes oferecer respostas construídas e assumidas em conjunto e desse modo evitar aquelas tradicionais lições impessoais, e, portanto, inócuas.

A realização da missão evangelizadora da universidade católica exige especificidade, pois não coincide com quaisquer outras propostas ou ações pastorais que podem ser exitosas em outros contextos, mas são inadequadas para o ambiente universitário, principalmente no momento atual, caracterizado pelo crescente descrédito, por parte de muitos jovens, em relação às religiões 
tradicionais. A administração de sacramentos, pregações e práticas piedosas podem até ter lugar e fazer bem em alguns casos, mas não constituem como outrora a essência da missão de evangelização da universidade católica.

\section{3) Desejos e perspectivas em relação às juventudes no meio universitário}

Os jovens universitários contemporâneos têm acesso cada vez mais facilitado aos meios de informação, o que favorece que tenham, ao menos, conhecimentos gerais muito mais disponíveis do que puderam ter as gerações anteriores, inclusive recentes; não obstante o notável avanço tecnológico, a humanização dos universitários tem sido mais fragmentada devido a vários fatores como a desestruturação das famílias, a mercantilização que prepondera nos mais diversos segmentos da sociedade, os conflitos entre os próprios jovens que ocasionam solidão, desilusão e desorientação existencial (Ribeiro,2009). Todos esses são problemas muito sérios, diante dos quais a universidade encontra dificuldades quando se propõe a interagir efetivamente.

Na universidade católica, não é raro acontecer um hiato entre a dimensão acadêmica e a evangelização; isso ocorre, principalmente, porque há falta de unidade de critérios quanto a como se deve evangelizar nos tempos atuais, uma vez que muitos docentes se limitam a transmitir conhecimentos sobre as suas respectivas disciplinas, sem cumprir a função de colaborar em vista de uma formação integral dos estudantes. São grandes os desafios postos às universidades católicas em relação à evangelização do mundo intelectual, a ser realizada por meio da inculturação do evangelho e não por doutrinação (CNBB, 2007).

O propósito existente em toda universidade de "busca pela verdade" como exercício específico da ciência tem, na universidade católica, o caminho da fé para chegar à Verdade Suprema, Deus; e superando os preconceitos científicos ou até teológicos entrar em diálogo com a ciência para descobrir novos caminhos para ter acesso a Cristo, em quem confluem todas as verdades e a partir de quem se pode projetar uma investigação rumo a uma sociedade com critério de justiça e a convicção de que a universidade católica está a serviço da sociedade para ajudá-la nos muitos problemas que a afligem. Essa 
busca pela verdade contempla uma interdisciplinaridade entre as mais diversas áreas e pressupõe igualmente a transdisciplinaridade que visa ir além das particularidades de cada disciplina isolada. Manter a coerência entre a expectativa criada ao apresentar propostas que motivem o ingresso e o panorama de realização profissional que sucede à graduação é um grande desafio para a universidade católica.

$\mathrm{Na}$ realidade atual da sociedade globalizada e mercantilista, prepondera a competitividade que favorece o eclipse dos interesses axiológicos (Benedetti, 2003). A consciência de que a realização plena do ser humano pode se encontrar ou, pelo menos, ter referência na vivência da mensagem de Jesus presente nos evangelhos traz à pastoral da cultura desafios que devem ser tratados no âmbito do diálogo fé e cultura e serem acolhidos pela universidade católica para repensar sua posição no mundo, suas funções à luz de sua identidade e missão.

É impossível não reconhecer que entre o conteúdo presente nos catecismos e o que os universitários atuais pensam, crêem e expressam em matéria de religião há divergências evidentes. $O$ contato e o respectivo diálogo cotidiano com jovens universitários permite a constatação da emergência de abordagem das questões relacionadas mais diretamente à religião e ao diálogo fé e cultura, tais como: se Deus é o único absoluto, que sentido e que consequências há em absolutizar uma religião? A fé é para ser vivida, se falta coerência entre a fé e a vida haverá que ser mudado o conteúdo da religião ou o comportamento pessoal? A Igreja deve se conformar com a diminuição dos fiéis ou ir em busca da maioria que está se afastando? Uma pessoa verdadeiramente religiosa é a que cumpre os mandamentos de uma religião ou a que vive os compromissos que nascem de uma experiência pessoal de fé? Qual deve ser o papel de quem está evangelizando quando a crença em um Deus transcendente não está em harmonia com as vivências humanas? Os canais pelos quais Deus se manifesta são sempre aqueles estabelecidos por uma igreja, ou poderiam surgir outros como sendo frutos da criatividade dos filhos de Deus? Quanto à acolhida e ao diálogo com as culturas, tradições, religiões e suas atitudes críticas, que comportamentos pessoais, familiares e sociais não promovem a dignidade humana e que novos modelos de ação serão necessários? Considerar a fé articulada com a cultura favorece o desmascaramento 
de ídolos, de personalismos messiânicos, de piedade mágica? O valor formativo da fé está sendo considerado suficientemente, está indo além do fomento de rituais piedosos, da transmissão de doutrinas exclusivas da religião?

Esse mesmo contato com os universitários permite constatar também questões de cunho pessoal (ligadas ao seu cotidiano) e outras que constituem desafios a serem respondidos pela universidade: como Jesus Cristo se faz presente na vida de maneira testemunhal para além do nível das simpatias pessoais? Como se pode desenvolver, a partir da cultura, a dignidade da vida humana em vistas de um humanismo integral? Como favorecer que a universidade seja uma comunidade de comunidades, na qual as relações entre as pessoas sejam orientadas pela ética do cuidado e não sejam reféns das leis do mercado? Como distinguir a sabedoria humana do conhecimento digital e como ajudar que se chegue a ela? Como lograr a integração do saber frente ao incremento da superespecialização? Como promover a síntese entre conhecimento particular inter e transdisciplinar? (Sommerman, 2008:31). Como possibilitar que a universidade católica forme pessoas e não apenas profissionais?

\section{Conclusão}

As juventudes podem ser abordadas por diferentes aspectos. A visão biocronológica, que define a juventude em termos de idade, a define como etapa de transição; a visão psicológica vê a juventude como uma etapa de construção da identidade, durante a qual o jovem tem muitas opções e define sua vocação. Já a visão sociológica vê a juventude como um grupo social, diferenciando-o em vários setores: estudantes, universitários, jovens em situações críticas, indígenas, operários/trabalhadores e outros. A visão cultural-simbólica vê a juventude em seu universo cultural a partir do qual constrói símbolos identitários; pode-se ainda mencionar uma visão jurídica ou legal de juventude. Essas visões são obviamente distintas, mas não são excludentes (Dick, 2003:15), a própria definição de juventude pode ser desenvolvida por uma série de pontos de partida: como uma faixa etária, um período da vida, um contingente populacional, uma categoria social, uma geração. Existem, contudo, elementos comuns a todos os jovens, por isso é necessário evitar uma visão fragmentada da juventude. É importante enfatizar, novamente, que não existe 
somente uma única juventude, nem um único perfil de jovem. O presente artigo é restrito à juventude universitária e sua relação com suas realidades sociais, sua religiosidade, sua vivência da fé e da espiritualidade cristã. Contudo, a juventude universitária é apenas uma dentre muitas e, mesmo no seu interior, há inúmeras diferenças marcadas pelas carreiras distintas e pelas desigualdades sociais que atravessam esta condição, como vimos. Portanto, é válido constatar que cresce a compreensão que existem várias juventudes, definidas e caracterizadas segundo diferentes situações, vivências e identidades socioculturais. Mais abrangente que "juventude" é o termo "jovialidade" que é uma condição inerente ao ser humano e não restrito a uma mera fase temporal da vida.

A pergunta que intitula este artigo - juventude, caminho aberto? - não é para ser respondida apenas pelos adultos, pois os jovens buscam apoio, aceitam dialogar, contudo, cada vez mais rechaçam que outros decidam por eles. Como educadores e evangelizadores devemos interagir, sem medo, com as juventudes, a fim de que juntos possamos abrir caminhos para a promoção da dignidade humana que, obviamente, deve incluir todos os seres humanos, sem nenhuma exceção.

\section{Referências bibliográficas}

BENEDETTI, Luiz Roberto. Entre Pastoral e Administração: Dilema da Universidade Católica. REB, Petrópolis, n.251, p.570-81, 2003.

BINGEMER, Maria Clara L. Ser jovem em tempos tenebrosos. In: Jornal do Brasil, 8/11/ 2018.

CNBB. Juventude caminho aberto. São Paulo: Salesiana, 1992.

Evangelização da Juventude - Desafios e Perspectivas Pastorais. Itaici: 45ª- Assembleia Geral, maio de 2007.

DICK, Hilário. Gritos silenciados, mas evidentes. Jovens construindo juventude na História. São Paulo: Loyola, 2003.

FRANCISCO. Laudato Si': sobre o cuidado da casa comum. São Paulo: Paulus, 2015.

. Carta aos jovens do Brasil, por ocasião do encerramento do Projeto Rota 300, 3 jul. 2017.

FRANCO, Marielle. Carta para os bolsistas da universidade: "Aos "bastardos da PUC", com carinho". 2017. Disponível em: https://piaui.folha.uol.com.br/aos-bastardos-da-PUC-com-carinho/ Acesso: 18/11/2018.

LIBANIO, João Batista. Para onde vai a juventude. São Paulo: Paulus, 2011. 
RIBEIRO, Jorge Cláudio. Religiosidade jovem, pesquisa entre universitários. São Paulo: Loyola e Olho d’Água, 2009.

SILVA, Jailson de Souza e. Por que uns e não outros? Caminhada de jovens pobres para a universidade. Rio de Janeiro: Sete Letras, 2003.

SIQUEIRA, Josafá. Reflexões do Mundo Universitário. Rio de Janeiro: Editora PUC Rio, 2018.

SOMMERMAN, Américo. Inter ou transdisciplinaridade? São Paulo: Paulus, 2008.

ZAGO, Nadir. Do acesso à permanência no ensino superior. Revista Brasileira de Educação, v.11, n.32. 2006. 